\title{
Humane killing of fish for scientific research: a comparison of two methods
}

J. J. BLESSING ${ }^{*}$, J.C. MARSHALL ${ }^{\S}$ AND S.R. BALCOMBE ${ }^{\S \S}$

$\S$ Queensland Department of Environment and Resource Management, 120 Meiers Rd, Indooroopilly, QLD, 4068, Australia

$\S \S$ Australian Rivers Institute, Griffith University, Nathan, QLD, 4111, Australia

\begin{abstract}
Two killing methods were compared on the Clupeid, bony bream, Nematolosa erebi and found that ice-slurry immersion was more humane than benzocaine overdose. The use of ice-slurry for killing $N$. erebi should be accepted as a standard humane method and considered similarly for other warm-water species.
\end{abstract}

KEYWORDS: euthanasia, ethics, benzocaine, ice-slurry, anaesthetic, Nematalosa erebi

\footnotetext{
* Author to whom correspondence should be addressed. Tel +61 (0) 73896 9879; fax +61 (0)7 3896 9172; email: Joanna.Blessing@derm.qld.gov.au
} 
Many research projects investigating the ecology of fish or their responses to management interventions require data to be collected from representative specimens that are captured and killed. Instances in which data can only be collected from dead fish include dietary investigations from stomach contents (e.g. Sternberg et al., 2008), stable isotope analyses from muscle tissue (e.g. Hesslein et al., 1991), fish age and growth examinations from otoliths (e.g. Crook et al., 2006) and reproductive autecology studies from staging the development of gonads (e.g. West, 1990). Sometimes alternative approaches using non-lethal methods can be employed, such as using fin-clips instead of fish muscle tissue for genetic analyses (e.g. Wasko et al., 2003), but in most cases, data of these types can be collected only from dead specimens.

However, the killing of animals for scientific purposes requires ethical considerations. Here the distinction is made between humane killing, where animals are killed humanely for research purposes as distinct from euthanasia where animals are killed humanely to alleviate pain or suffering (National Health and Medical Research Council \{hereafter, NHMRC\}, 2004). Before killing fish to gather data, the need for the data must be both reasonable and well justified and the methods employed in its collection must be as humane as possible including appropriate handling, water quality, holding densities and killing method (Huntingford et al., 2006). In Australia all scientific research on animals, including fish requires ethical clearance by animal ethics committees as specified in an Australian code of practice (NHMRC, 2004). There are many methods used to humanely kill fish such as pithing, exsanguination, overdose of anaesthetic and immersion in an ice-slurry (eg. Barker et al., 2002). The current best practice in Australia recommended to ethics committees for both humane 
killing and euthanasia of fish are chemical methods (such as benzocaine and MS222), while hypothermia (e.g immersion in ice-slurry) is not recommended (NHMRC, 2008).

This paper reports on the results of a pilot study to contrast two fish killing methods as requested by an ethics committee after reticence was voiced about using a chemical compared to the preferred method of ice-slurry immersion. The aim was to ensure that the killing method was humane in that fish did not exhibit stressful behaviour prior to losing consciousness (NHMRC, 2004) and to ensure the fish were rendered insensible as quickly as possible to assess the effectiveness of the killing method (Kestin et al, 2002). The aim was, therefore, to compare the behavioural stress response and the associated time taken to lose equilibrium and reach the death endpoint by a small to medium bodied Australian freshwater Clupeid bony bream, Nematalosa erebi (Günther, 1868) in response to benzocaine overdose and ice-slurry immersion.

An overdose of benzocaine kills fish by depressing their central nervous system activity and because it is considered an effective and humane mode of euthanasia it is recommended by many guidelines (European Commission, DGXI Working Party, 1996; Barker et al., 2002; Reilly et al., 2001; European Commission, DGXI - Working Party, 1997) Lipid soluble anaesthetics such as benzocaine enter nerve-cell membranes and inhibit nerve conduction by physically blocking sodium channels (Cakir \& Strauch, 2005). Benzocaine powder is dissolved in alcohol or acetone to make it water soluble and bioactive. In this form it readily enters fish by crossing biological membranes, chiefly via the gills (Hunn \& Allen, 1974). Nonchemical methods such as immersion in ice-slurry or a knock-out blow to head are 
common practice in the food industry, but are perhaps less widely employed in ecological research.

The traditional method of immersing fish in an ice-slurry to achieve death by hypothermia relies on lowering the core body temperature resulting in anaesthesia and subsequent death. This has been approved by some fish euthanasia guidelines (Barker et al., 2002), but rejected by others (e.g. European Commission, DGXI - Working Party, 1996; Barker et al., 2002; Reilly et al., 2001; European Commission, DGXI Working Party, 1997). Rejections of the method have been based firstly, on evidence that the method potentially causes an initial period of discomfort due to ice crystal formation both on the skin and within the body (Reilly et al., 2001), and secondly on a potentially long treatment time before achieving death (Van De Vis et al., 2003) because of the poor thermal conductivity of tissues surrounding the brain (European Commission, DGXI - Working Party, 1996). It should be noted, however, that studies of the use of ice-slurry for fish slaughter (in the food industry) have often been undertaken on large cold-water species from the Northern Hemisphere, such as turbot (Psetta maxima), gilt-headed sea bream (Sparus auratus) and Atlantic salmon (Salmo salar) (Van De Vis et al., 2003; Morzel et al., 2003). Current Australian guidelines are based on these northern hemisphere studies (Reilly et al., 2001), but it is not clear if such assumptions are universally valid, particularly for small to medium bodied, warm-water fish.

Nematalosa erebi is one of the most widespread of Australia's freshwater fishes, and is typically abundant where it occurs. It is potamodromous, primarily a benthic detritivore/ algivore, and has a maximum length of approx $400 \mathrm{~mm}$ living for up to five years ( Pusey et al., 2004; Sternberg et al., 2008). Nematalosa erebi are renowned for their susceptibility to handling stress (Gehrke, 2003). Owing to this 
susceptibility, they were considered to be likely to exhibit behavioural stress responses to different killing methods and therefore a suitable species for this investigation. Fish were collected from Bjelke-Petersen Dam on the Burnett River, South-East Queensland, Australia (E 26.3054, S 151.977), on the $4^{\text {th }}, 5^{\text {th }}$ and $10^{\text {th }}$ of January 2007 using fyke and seine netting as per methods outlined in Arthington et al., (2005). Forty-one $N$. erebi (28-135 $\mathrm{mm} \mathrm{L}_{\mathrm{s}}$ ) were retained and stored in a 30 x $60 \mathrm{x}$ $50 \mathrm{~cm}$ shaded and aerated plastic container containing lake-water. This maintained water temperature within $2^{\circ} \mathrm{C}$ of the dam water temperature of $25.5^{\circ} \mathrm{C}\left(4^{\text {th }}\right.$ and $5^{\text {th }}$ January) and $27.0^{\circ} \mathrm{C}\left(10^{\text {th }}\right.$ January). Fish were held for a maximum of 4 hours in these conditions, and fish used in this study were visually judged to be in good health, with no obvious display of stress such as 'gulping', erratic swimming, 'flashing' or colour change (Barker et al., 2002).

Individual fish were randomly assigned to one of two treatments: ice slurry or benzocaine. The sequence of treatments was also randomised. All treatments were performed onsite. Fish were processed individually, removed from the storage container with an aquarium net and placed into an $11 \mathrm{~L}$ glass aquarium, with a separate aquarium used for each treatment type to avoid cross-contamination of treatments. Temperature and $\mathrm{pH}$ of the water in the holding tank and the treatment tank was recorded. Behaviour in each fish treatment was recorded by a video camcorder and timed until the end point was reached, which was considered to be the combination of loss of equilibrium and cessation of opercular movement (eg Kestin et al., 2002). Fish were left in the treatment for one additional minute to be certain that a comatose state or death was achieved, and then immediately transferred to a freezer to ensure death. 
For the benzocaine treatment, $0.5 \mathrm{~g}$ benzocaine was dissolved in $42 \mathrm{~mL}$ ethanol. Lake water ( $5 \mathrm{~L}$ ) was introduced into the benzocaine treatment aquarium and the benzocaine solution added. This yielded a benzocaine concentration of $100 \mathrm{mgL}^{-1}$, which is the recommended dose for fish euthanasia (Barker et al., 2002). Following each euthanasia trial, the aquarium was emptied into a waste container and rinsed with lake water in preparation for the next benzocaine trial.

For the ice-slurry treatment a cold-water reservoir of ice and lake water was maintained in a $30 \times 60 \times 50 \mathrm{~cm}$ plastic container. For each trial $5 \mathrm{~L}$ of cold-water from the reservoir was mixed with $5 \mathrm{~L}$ of ice in the ice-slurry treatment aquarium. The slurry was mixed until water temperature was between 0 and $2^{\circ} \mathrm{C}$ as recommended for fish killing (Van De Vis et al., 2003). The ice in the tank was held back by a spatula while a fish was placed into the ice-cold water. Following each euthanasia treatment, the tank was emptied, and rinsed with lake water ready for the next ice-slurry treatment.

Video footage was reviewed and the frequency, duration and intensity of behavioural signs of stress recorded, such as 'skitzing' behaviour (jerky type stress movements) and opercular flaring (Barker et al., 2002). Abnormal swimming behaviour was also recorded (i.e. different to that observed by us in the past on other captive $N$. erebi). Time until loss of equilibrium was also confirmed from the footage to verify earlier field observations.

It was expected that the effect of treatments on fish behaviour and death would be somewhat influenced by individual fish length. Hence, linear regressions were used to test the association between fish standard length $\left(\mathrm{L}_{\mathrm{s}}\right)$ and time to reach equilibrium and death. Analysis of Covariance (ANCOVA) were then used to test differences between the two treatment effects on time to reach equilibrium and death, with 
treatment as a fixed effect and fish $L_{s}$ as a covariate. To meet the assumptions of regression and ANCOVA all factors were $\log _{e}(\mathrm{X})$ transformed. All analyses were performed using Systat for Windows 11.00.01 (SSI, 2004).

The time taken for fish in the ice treatment to lose equilibrium ranged between 0.04 and 0.35 minutes, while the range was between 0.11 and 26.3 minutes in the benzocaine treatment. There was no relationship between $L_{s}$ and time to loss of equilibrium in the benzocaine treatment, while there was a significant positive relationship between fish length and time in the ice treatment [Fig. 1(a)]. Clearly, the time taken to lose equilibrium in the benzocaine treatment $(2.02 \pm 1.30 \mathrm{~min})$ was higher than that for the ice treatment $(0.10 \pm 0.02 \mathrm{~min})$. This result was confirmed by ANCOVA (d.f. $=1, \mathrm{P}<0.001$, covariate $\log _{\mathrm{e}} \mathrm{L}_{\mathrm{s}}: \mathrm{P}<0.048$ ).

The time taken for fish in the ice treatment to die ranged between 0.07 and 1.47 minutes, while the range was between 0.21 and 29.5 minutes in the benzocaine treatment. There was no relationship between $\mathrm{L}_{\mathrm{s}}$ and time to death in the benzocaine treatment, while there was a significant positive relationship between fish length and time in the ice treatment [Fig. 1(b)]. Fish took significantly longer to reach the death endpoint in the benzocaine treatment $(3.6 \pm 1.60 \mathrm{~min})$ than that for the ice treatment $(0.34 \pm 0.08 \mathrm{~min})\left(\right.$ ANCOVA d.f. $=1$, covariate $\left.\log _{\mathrm{e}} \mathrm{L}_{\mathrm{s}}: \mathrm{P}=0.001\right)$

Most individuals (78 \%) in the benzocaine treatment exhibited what appeared to be a distressed behaviour pattern of prolonged rapid swimming along the tank floor with a head-down attitude and rapid operculum movement. The remaining 22\% displayed similar behaviour but with a head-upwards attitude gasping at the water surface. Two individuals could not be visually assessed on the video footage so were excluded from these calculations. This behaviour was not observed at all in ice-slurry treatment individuals, who in all cases reacted with a brief burst of high-speed 
swimming when introduced to the treatment, followed by rapid slowing of motion and death. The long duration of stress-related behaviour in benzocaine treated individuals suggests greater stress for fish in the benzocaine treatment. There were no other stress behaviours observed in either treatment.

Given the ethical requirements for fish killing to be both rapid and gentle, the results provide compelling evidence favouring the use of ice-slurry over benzocaine for the humane killing of small to medium sized $N$. erebi. The ice-slurry method produced more rapid loss of equilibrium, more rapid death and generated less stressful behaviour. In contrast, most individuals killed by benzocaine displayed obvious distress. Furthermore, it was possible to predict the likely time to death for a given fish length in the ice-slurry treatment. In the benzocaine treatment there was no such predictability in relation to length and the extreme outliers recorded demonstrate that individual fish could well be subject to very long exposure to stress under this treatment.

A further advantage of ice-slurry is its simplicity to administer and relative safety of use for both the operator and the environment. Ice requires no specific handling techniques or protective equipment. Benzocaine on the other hand, is potentially hazardous to the operator, requiring care of use and personal protective equipment. It also needs to be sourced from specialist suppliers and potentially harmful to the environment with care needed to be taken in its disposal (CHEMWATCH, 2006).

The contrast between the high effectiveness of ice-slurry in this study and earlier unsatisfactory results e.g. (Van De Vis et al., 2003; Morzel et al., 2003) may be explained by important differences in the size and physiology of the fish used. As outlined above, prior evaluations of ice-slurry slaughter methods have focused on fish 
species that were both large-bodied and from cold-climate regions, whereas this study used medium bodied fish collected from a sub-tropical lake. It can therefore be contended that both the size difference and the difference in climate are important in understanding these divergent results.

Fish size is important in determining the effectiveness of humane killing by ice-slurry because it determines the rate of temperature reduction of the fish body. The rate of heat loss via thermal conduction from a body is proportional to its surface area. However, the quantum of heat loss required to lower the core temperature of an organism by $1^{\circ} \mathrm{C}$ (its cooling resistance) is a function of its body mass, meaning (assuming equal thermal conductivity characteristics) large fish need to lose more heat than small fish to achieve the same reduction in core temperature (Marchand, 1996).

The actual temperature reduction needed to cause death depends on the susceptibility of individual fish to cold (Brett, 1956). Variation in the cold tolerance of fish is correlated with their geographical distributions, with species and populations from warm lower-latitude areas much more cold-susceptible than those from naturally colder high-latitude regions (Cnaani et al., 2000). The fish used for this study were from a warm sub-tropical region with a natural minimum winter water temperature of approximately $11^{\circ} \mathrm{C}$ (Deparment of Environment and Resource Management, unpublished data). This is considerably warmer that the temperature of the ice slurry treatment and it is likely that the body temperature at which $N$. erebi succumbs to cold is higher than for fish adapted to life in cold-water. Ice slurry immersion has been used as an effective humane killing method in other Australian inland (warm-water) species of fish including the larger bodied yellowbelly, Macquaria ambigua (S. Balcombe, pers.obs). 
Thus body size and species-specific thermal tolerance are both important in determining the effectiveness and appropriateness of the ice-slurry method for the humane killing of fish. Based on understandings of these two factors, it is suggested that ice-slurry is a suitable killing method for all small-medium bodied fish species with cold tolerance thresholds higher that the $2^{\circ} \mathrm{C}$ upper temperature of an ice-slurry. Additional suggestions are that further trials should be undertaken on other warmwater species and over greater length ranges than used here to ascertain the applicability of using ice-slurry on different size classes and species of fish.

These results demonstrate the difficulty of providing "blanket” ethical guidelines for scientific methods across fish sizes and species (e.g NHMRC, 2004; 2008). For example, it can not be assumed that dose rates of anaesthetics are consistent across species and developmental stages of fish. It can also not assume, therefore, that the successful use of anaesthetic overdose as a humane killing method on one species can be transferred to another. However, from this study the use of iceslurry should be advocated as a humane killing method to be adopted as a standard operating procedure on $N$. erebi for all Australian animal ethics committees. Furthermore, it is also proposed that ice-slurry immersion should be considered as an accepted humane method of killing fish for research subject to appropriate trials on other warm-water species.

\section{Acknowledgements}

We would like to thank Louisa Davis and Norbert Menke for their help with fish collection. This work was conducted under the Queensland Department of Primary Industries and Fisheries (QDPI\&F) General Fisheries Permit PRM03013I, and under QDPI\&F Animal Ethics Permit PAEC061103. We would like to thank the members 
of the Natural Resources and Water Pest Animal Ethics Committee for their involvement in this study. The work was funded by DERM as part of the development of the Stream and Estuary Assessment Program. Joel Huey, Melanie Shaw, and Glenn McGregor reviewed drafts of this manuscript and their helpful comments improved the final version.

\section{References}

Arthington A.H., Balcombe S.R., Wilson G.A., Thoms M.C. \& Marshall J. (2005)

Spatial and temporal variation in fish-assemblage structure in isolated waterholes during the 2001 dry season of an arid-zone floodplain river, Cooper Creek, Australia. Marine and Freshwater Research, 56, 25-35.

Barker D., Allan G.L., Rowland S.J. \& Pickles J.M. (2002) A Guide to Acceptable Procedures and Practices for Aquaculture and Fisheries Research. Port Stephens, NSW: NSW Fisheries Animal Care and Ethics Committee, Port Stephens Fisheries Centre, New South Wales.

Brett J.R. (1956) Some principles in the thermal requirements of fishes. Quarterly Review of Biology, 31, 75-87.

Cakir Y. \& Strauch S.M. (2005) Tricaine (MS-222) is a safe anesthetic compound compared to benzocaine and pentobarbital to induce anesthesia in leopard frogs (Rana pipiens). Pharmacological Reports, 57, 467-474.

CHEMWATCH 16627, NC317TCP (2006) Chemwatch Material Safety Data Sheet (REVIEW): Benzocaine. 1-11. Website: http://fortuna.itc.griffith.edu.au/chemwatch/ 
Cnaani A., Gall G.A.E. \& Hulata G. (2000) Cold tolerance of tilapia species and hybrids. Aquaculture International, 8, 289-298.

Crook D.A., Macdonald J.I., O'Connor J.P. \& Barry B. (2006) Use of otolith chemistry to examine patterns of diadromy in the threatened Australian grayling Prototroctes maraena. Journal of Fish Biology, 69, 1330-1344.

European Commission, DGXI - Working Party (1997) Euthanasia of experimental animals. Part 2. Laboratory Animals, 31, 1-32.

European Commission, DGXI - Working Party (1996) Euthanasia of experimental animals. Part 1. Laboratory Animals, 30, 293-316.

Gehrke, P. (2003) Preliminary assessment of oral rotenone baits for carp control in New South Wales. in: Proceedings of the New Zealand workshop on Pest Fish Mangement, May 2001, Hamilton, New Zealand: New Zealand Department of Conservation: 143-154.

Hesslein R.H., Capel M.J., Fox D.E. \& Hallard K.A. (1991) Stable isotopes of sulfur, carbon, and nitrogen as indicators of trophic level and fish migration in the lower Mackenzie River basin, Canada. CAN.J.FISH.AQUAT.SCI., 48, 2258-2265.

Hunn J.B. \& Allen J.L. (1974) Movement of drugs across the gills of fishes. Annual Review of Pharmacology and Toxicology, 14, 47-55.

Huntingford F.A., Adams C., Braithwaite V.A., Kadri S., Pottinger T.G., Sandøe P. \& Turnbull J.F. (2006) Current issues in fish welfare. Journal of Fish Biology, 68, 332372. 
Kestin, S.C., Van De Vis J.W. (2002) Protocol for assessing brain function in fish and the effectiveness of methods used to stun and kill them. Veterinary record, 150, 302307.

Marchand P.J. (1996) Life in the cold, an introduction to winter ecology, third edition. University Press of New England, Lebanon, NH. 304pp.

Morzel M., Sohier D. \& Van De Vis H. (2003) Evaluation of slaughtering methods for turbot with respect to animal welfare and flesh quality. Journal of the Science of Food and Agriculture, 83, 19-28.

NHMRC (2004) $7^{\text {th }}$ edition.Australian Code of Practice for the care and use of animals for scientific purposes. Commonwealth of Australia. Canberra, Australia: Australian Government Publishing Service. 84pp.

NHMRC (2008) Guidelines to promote the wellbeing of animals used for scientific purposes: the assessment and alleviation of pain and distress in research animals. Commonwealth of Australia. Canberra, Australia: Australian Government Publishing Service

Pusey B.J., Kennard M.J. \& Arthington A.H. (2004) Freshwater Fishes of Northeastern Australia. CSIRO Publishing: Collingwood, Victoria, Australia.684pp

Reilly J.S., Rose M.A., Fenwick D., Harris I., Blackshaw A.W., Blackshaw D.K. \& Shaw F.D. (2001) Euthanasia of Animals Used for Scientific Purposes. Website: http://www.monash.edu.au/researchoffice/animal/assets/resources/euthanasia.pdf 
Sternberg D., Balcombe S., Marshall J. \& Lobegeiger J. (2008) Food resource variability in an Australian dryland river: Evidence from the diet of two generalist native fish species. Marine and Freshwater Research, 59, 137-144.

Systat Software, Inc. (SSI), (2004). Systat ${ }^{\circledR}$ for Windows ${ }^{\circledR}$. (Richmond: CA).

Van De Vis H., Kestin S., Robb D., Oehlenschlager J., Lambooij B., Munkner W., Kuhlmann H., Kloosterboer K., Tejada M., Huidobro A., Ottera H., Roth B., Sørensen N.K., Akse L., Byrne H. \& Nesvadba P. (2003) Is humane slaughter of fish possible for industry? Aquaculture Research, 34, 211-220.

Wasko A.P., Martins C., Oliveira C. \& Foresti F. (2003) Non-destructive genetic sampling in fish. An improved method for DNA extraction from fish fins and scales. Hereditas, 138, 161-165.

West G. (1990) Methods of assessing ovarian development in fishes: A review. Australian Journal of Marine and Freshwater Research, 41, 199-222. 
FIG. 1. Scatterplots between $\log _{\mathrm{e}}$ times and $\log _{\mathrm{e}}$ standard length (mm) with two treatment variables: benzocaine (solid symbols) and ice-slurry (open symbols and dashed line). (a) Loge time to equilibrium loss by bony bream. Significant linear relationships are shown on plot: Benzocaine (No significant relationship); Ice (Loge time $=0.84 \log _{\mathrm{e}} \mathrm{L}_{\mathrm{s}}-5.73, R^{2}=0.5, \mathrm{~F}_{1,19}=15.5, p<0.001$ ). (b) $\log _{\mathrm{e}}$ time to death of bony bream. Significant linear relationships are shown on plot: Benzocaine (No significant relationship); Ice $\left(\log _{\mathrm{e}}\right.$ time $=1.74 \log _{\mathrm{e}} \mathrm{L}_{\mathrm{s}}-8.39, \mathrm{R}^{2}=0.89, \mathrm{~F}_{1,19}=150, p$ $<0.001)$
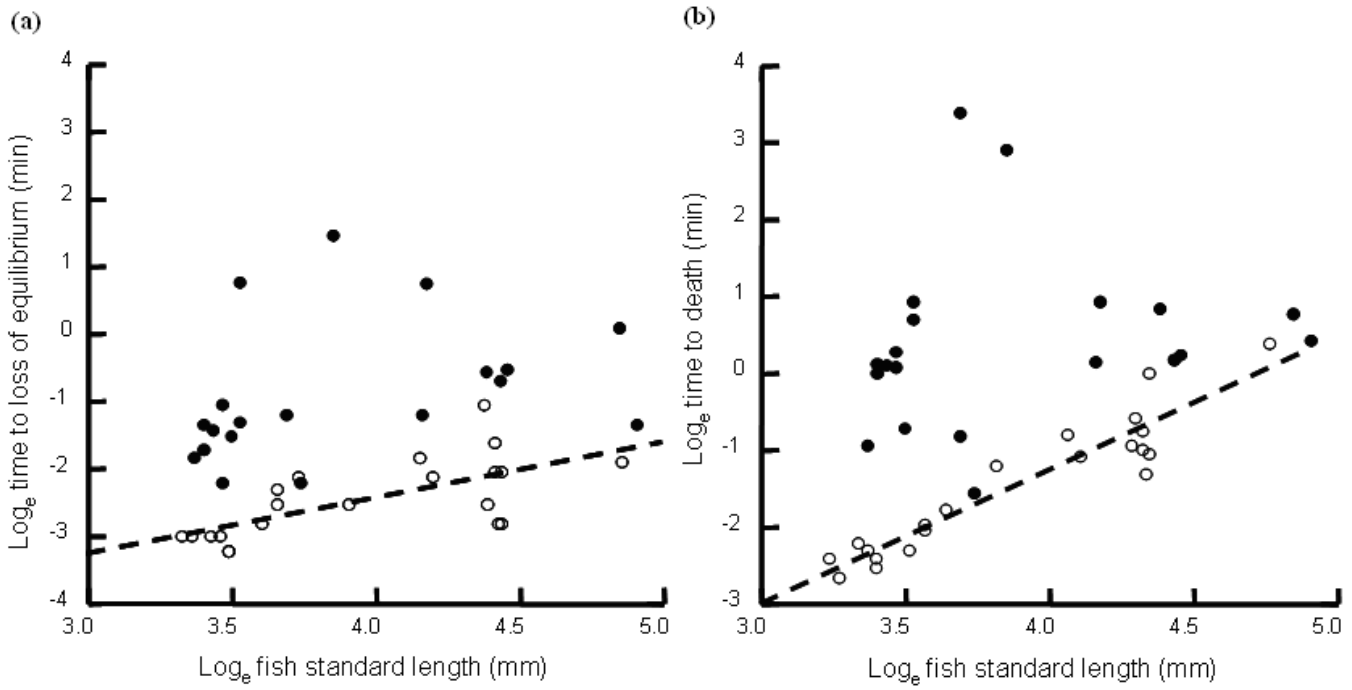